\title{
各層を単位とするサブシステムの同定に基づく剛性のへルスモニタリング \\ STRUCTURAL HEALTH MONITORING OF STORY STIFFNESS \\ BASED ON IDENTIFICATION OF SUBSYSTEM REPRESENTING SPECIFIC STORY OF A BUILDING
}

\author{
仁田佳宏*, 西谷 章** \\ Yoshihiro NITTA and Akira NISHITANI
}

\begin{abstract}
This paper presents a unique methodology of monitoring the reduction in story stiffness of a building integrating a filtering technique. In the proposed methodology, identification is conducted based on the subsystem representing the behavior of specific story. The natural frequencies identified with respect to these subsystems give useful information for evaluating the story stiffness. In estimating such a natural frequency of the subsystem, the subspace identification technique is utilized along with the measurement of only the right upper and lower stories' absolute accelerations. The validity of the proposed methodology is demonstrated by conducting computer simulations and scale-model experiments.
\end{abstract}

Keywords : Structural health monitoring, System identification, Story stiffness, Subspace identification, Acceleration measurement 構造ヘルスモニタリング、システム同定、層剛性、部分空間同定法、加速度計測

\section{1. はじめに}

計測制御技術やコンピュータ技術の発展とともに、建築構造物に おけるシステム同定は、建築構造物の動特性把握のみならず制震 (振) 構造物の性能評価や構造ヘルスモニタリングなどに用いられ、 その応用範用が拡がっている。特にシステム同定の構造へルスモニ タリングへの応用は、ノースリッジ地震や兵庫県南部地震を契機に、 損傷した構造物の安全性評価や損傷箇所の特定、損傷程度の把握を 行うための有効な手段として、重要性が増大している。

一般的に構造へルスモニタリングには、(1) 損傷有無の把握、(2) 損 傷箇所の特定、(3) 損傷程度の評価、(4) 損傷した構造物の性能評価 の 4 つの段階が存在する 1- 4)。既往の手法は、損傷有無の把握、損 傷箇所の特定に重点をおいたものが多く、定量的な建築構造物の ルスモニタリングを行うためには、更なる研究が必要とされている。

構造ヘルスモニタリングの手法としては、加速度応答の共分散か らモ一ド特性を求めるもの ${ }^{5,6)}$ をはじめとする、モード特性を同定 するもの ${ }^{7-9)}$ と、層岡性などの物理特性を同定するもの ${ }^{10-12)}$ の大き く2つがある。モード特性を同定して用いる手法は、必ずしも全層 の応答計測を行わなくても、損傷の有無を把握できる。しかし、よ り詳細な構造へルスモニタリングである損傷箇所の特定や損傷程度 の評価などを行うためには、全層の同期をかけた応答計測もしくは 高次モードまでの同定が必要となる。さらに、層剛性などを評価す
るためには、同定したモード特性から最小 2 乗法などを用いて物理 特性を求める必要があるものが多い。一方、物理特性を直接同定し て用いる手法は、そのまま層ごとの損傷の評価に結びつけることが できる。しかし、全層もしくは構造へルスモニタリングの対象層よ り上層の同期された応答計測を必要としたり、上層から順に構造へ ルスモニタリングする必要があるといった制約があり、利便性に欠 ける手法も少なくない。全層の同期した応答を計測することなく、 各層独立に、物理特性を直接同定し、構造ヘルスモニタリングを行 うことができれば、より簡便に多くの構造物に構造へルスモニタリ ングを適用できるようになると考えられる。このような手法の一つ として、対象層と上下層の加速度応答をフーリエ変換し、周波数領 域上で同定を行い、同定值の平均値もしくは振動数ぜロの極限值に より構造へルスモニタリングを行う手法 ${ }^{11,12)}$ が提案されている。た だし、これらの手法では、入力の周波数特性が同定結果に影響する 場合があるため、入力の周波数特性を考慮して同定を行う必要があ る。

そこで本研究では、対象層とその上下層の加速度応答計測のみを 用いた、時間領域での層剛性の構造へルスモニタリング手法を提案 する。ただし、本研究の構造ヘルスモニタリング対象は、多くの既 往の研究と同様に、せん断型構造モデルとして表すことのできる構 造物の柱損傷とする。提案手法は、既往の手法の多くと異なり、全
* 早稲田大学理工学部建築学科 専任助手 · 博士 (工学)

** 早稲田大学理工学部建築学科 教授. Ph. D. 功博
Research Assoc., Dept. of Architecture, Waseda University, Dr. Eng. Prof., Dept. of Architecture, Waseda University, Ph. D., Dr. Eng. 
層の応答を同期して観測する必要も、上層から順番に同定する必要 もない。本論文では、まず各層ごとにその層の特性を表すサブシス テムを定義し、つぎにこのサブシステムの同定結果を用いた構造へ ルスモニタリング手法を示す。本手法は、各層ごとにその層の特性 を表すサブシステムの固有振動数を同定し、損傷発生前後の同定し た固有振動数を比較することで、層岡性の剛性低下率を把握するた め、各層独立に層剖性の構造ヘルスモニタリングを行うことが可能 である。提案手法の有効性は、数值解析と小型構造物模型を用いた 実験により確認する。

\section{2. 構造ヘルスモニタリングの基本概念}

$N$ 層せん断型構造物の $i$ 層についての運動方程式を、 $(i-1)$ 層 を仮想的に地表面とみなして、通常とは少し違った次のような方程 式で表す。

$$
\begin{aligned}
m_{i} \ddot{d}_{i}+c_{i} \dot{d}_{i}+k_{i} d_{i}= & -m_{i}\left(\ddot{x}_{i-1}+\ddot{x}_{g}\right) \\
& +c_{i+1} \dot{d}_{i+1}+k_{i+1} d_{i+1}
\end{aligned}
$$

ただし、 $m_{i}$ は $i$ 層の質量、 $c_{i}$ は $i$ 層の减衰、 $k_{i}$ は $i$ 層の岡性、 $d_{i}$ は $i$ 層の層間変位、 $x_{i}$ は $i$ 層の構造物の地表面に対する相対変位、 $\ddot{x}_{g}$ は地表面加速度である。式（1）において、 $\ddot{x}_{i-1}+\ddot{x}_{g}$ を地表面 加速度、 $c_{i+1} \dot{d}_{i+1}$ と $k_{i+1} d_{i+1}$ を $i$ 層を表す質点に加わる入力とみ なせば、式 (1) は $i$ 層のみを表すサブシステムの運動方程式となる。

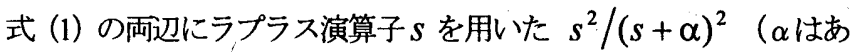
る実数）を乗じ、ラプラス演算子 $s$ が微分を表すことを考慮すると 13- 15)

$$
\begin{aligned}
& m_{i} \frac{s^{2} \ddot{d}_{i}}{(s+\alpha)^{2}}+c_{i} \frac{s^{2} \dot{d}_{i}}{(s+\alpha)^{2}}+k_{i} \frac{s^{2} d_{i}}{(s+\alpha)^{2}}= \\
& -m_{i} \frac{s^{2}\left(\ddot{x}_{i-1}+\ddot{x}_{g}\right)}{(s+\alpha)^{2}}+c_{i+1} \frac{s \ddot{d}_{i+1}}{(s+\alpha)^{2}}+k_{i+1} \frac{\ddot{d}_{i+1}}{(s+\alpha)^{2}}
\end{aligned}
$$

のようになり、質点に加わる入力をすべて加速度で表すことができ る。式（2）において、 $s^{2} /(s+\alpha)^{2}$ はハイパスフィルタを、 $s /(s+\alpha)^{2}$ は、ある一つの振動数にゲインのピークがある積分フ イルタを、 $1 /(s+\alpha)^{2}$ は2 階の積分の効果を持つローパスフィルタ を構成している ${ }^{14,15) 。 こ れ ら ~} 3$ 種類のフィルタは、状態空間表現を 用いることで、以下のように時間領域上で表される。

$s^{2} /(s+\alpha)^{2}$ を、状態空間表現で表すと、

$$
\begin{aligned}
& {\left[\begin{array}{l}
\dot{\xi}_{f 1} \\
\ddot{\xi}_{f 2} \\
\dot{\xi}_{f 2}
\end{array}\right]=\left[\begin{array}{ccc}
-\alpha & 0 & 0 \\
0 & -2 \alpha & -\alpha^{2} \\
0 & 1 & 0
\end{array}\right]\left[\begin{array}{c}
\xi_{f 1} \\
\dot{\xi}_{f 2} \\
\xi_{f 2}
\end{array}\right]+\left[\begin{array}{c}
2 \alpha \\
\alpha^{2} \\
0
\end{array}\right] u} \\
& x_{f}=u-\xi_{f 1}+\xi_{f 2}
\end{aligned}
$$

ただし、 $x_{f}$ はフィルタ出力を、 $u$ はフィルタ入力を表す。同様に して、 $s /(s+\alpha)^{2}$ は

$$
\begin{aligned}
& {\left[\begin{array}{l}
\dot{\xi}_{f 1} \\
\ddot{\xi}_{f 2} \\
\dot{\xi}_{f 2}
\end{array}\right]=\left[\begin{array}{ccc}
-\alpha & 0 & 0 \\
0 & -2 \alpha & -\alpha^{2} \\
0 & 1 & 0
\end{array}\right]\left[\begin{array}{c}
\xi_{f 1} \\
\dot{\xi}_{f 2} \\
\xi_{f 2}
\end{array}\right]+\left[\begin{array}{l}
1 \\
\alpha \\
0
\end{array}\right] u} \\
& x_{f}=\xi_{f 1}-\xi_{f 2}
\end{aligned}
$$

$1 /(s+\alpha)^{2}$ は、

$$
\left[\begin{array}{c}
\ddot{x}_{f} \\
\dot{x}_{f}
\end{array}\right]=\left[\begin{array}{cc}
-2 \alpha & -\alpha^{2} \\
1 & 0
\end{array}\right]\left[\begin{array}{l}
\dot{x}_{f} \\
x_{f}
\end{array}\right]+\left[\begin{array}{l}
1 \\
0
\end{array}\right] u
$$

と表せる。

$i$ 層の絶対加速度応答を出力 $y_{i}$ として、式 (2) を状態空間表現 で表すと

$$
\begin{aligned}
& \dot{X}_{i}=A_{i} X_{i}+B_{i} U_{i} \\
& y_{i}=C_{i} X_{i}+D_{i} U_{i}
\end{aligned}
$$

ただし、

$A_{i}=\left[\begin{array}{cc}-\frac{c_{i}}{m_{i}} & -\frac{k_{i}}{m_{i}} \\ 1 & 0\end{array}\right], \quad B_{i}=\left[\begin{array}{ccc}-1 & \frac{c_{i+1}}{m_{i}} & \frac{k_{i+1}}{m_{i}} \\ 0 & 0 & 0\end{array}\right]$,

$C_{i}=\left[\begin{array}{cc}-\frac{c_{i}}{m_{i}} & -\frac{k_{i}}{m_{i}}\end{array}\right], \quad D_{i}=\left[\begin{array}{lll}0 & \frac{c_{i+1}}{m_{i}} & \frac{k_{i+1}}{m_{i}}\end{array}\right]$,

$X_{i}=\left[\begin{array}{ll}\dot{x}_{f i} & x_{f i}\end{array}\right]^{T}, \quad U_{i}=\left[\begin{array}{lll}\ddot{x}_{g i} & u_{v i} & u_{d i}\end{array}\right]^{T}$,

$y_{i}=\frac{s^{2} \ddot{d}_{i}}{(s+\alpha)^{2}}, \quad \dot{x}_{f i}=\frac{s^{2} \dot{d}_{i}}{(s+\alpha)^{2}}, \quad x_{f i}=\frac{s^{2} d_{i}}{(s+\alpha)^{2}}$,

$\ddot{x}_{g i}=\frac{s^{2}\left(\ddot{x}_{i-1}+\ddot{x}_{g}\right)}{(s+\alpha)^{2}}, u_{v i}=\frac{s \ddot{d}_{i+1}}{(s+\alpha)^{2}}, \quad u_{d i}=\frac{\ddot{d}_{i+1}}{(s+\alpha)^{2}}$

ここで、式（8）で表されるサブシステムの固有振動数 $\omega_{i}$ と $i$ 層の 層剛性 $k_{i} 、 i$ 層の質量 $m_{i}$ の間には、次の関係が成り立つ。

$$
\omega_{i}^{2}=\frac{k_{i}}{m_{i}}
$$

損傷発生前後での質量の変動は微小と仮定すると、式（10）より 損傷発生前後のサブシステムの $\omega_{i}{ }^{2}$ を比較することで、層剛性の構 造ヘルスモニタリングが可能となる。以後、本論文では、式 (10) のサブシステムの $\omega_{i}{ }^{2}$ を「層岡性の評価値」と呼ぶこととする。サ ブシステムの固有振動数 $\omega_{i}$ は、構造ヘルスモニタリング対象層と その上下層の絶対加速度応答を計測して、部分空間同定法の一つで ある MOESP 法 (MIMO Output-Error State Space Model Identification) を用いて同定する 16-20)。以下に、MOESP 法による同定のアルゴリ ズムを示す。アルゴリズムは、次の(1)-(5)圤な。 
(1) MOESP 法では、まず入力と出力についての、ブロック行 $p 、 フ ゙$ ロック列 $q$ のブロックハンケル行列 ${ }^{21}$ 2. 2)からなる次のような行 列 $H$ を作成寸る。

$$
H=\left[\begin{array}{cccc}
U_{i}(0) & U_{i}(1) & \cdots & U_{i}(q-1) \\
\vdots & \vdots & & \vdots \\
U_{i}(p-1) & U_{i}(p) & \cdots & U_{i}(q+p-2) \\
y_{i}(0) & y_{i}(1) & \cdots & y_{i}(q-1) \\
\vdots & \vdots & & \vdots \\
y_{i}(p-1) & y_{i}(p) & \cdots & y_{i}(q+p-2)
\end{array}\right]
$$

ここで、 $U_{i}(j)$ は時刻 $j \times \Delta t$ における入力、 $y_{i}(j)$ は時刻 $j \times \Delta t$ における出力である。ただし、 $\Delta t$ はサンプリング時間間 隔を表す。

(2) 式（11）の行列 $H$ を RQ 分解 23$)$ 寸る。

$$
H=\left[\begin{array}{cc}
R_{11} & 0 \\
R_{21} & R_{22}
\end{array}\right]\left[\begin{array}{l}
Q_{1}^{T} \\
Q_{2}{ }^{T}
\end{array}\right]
$$

ただし、 $R_{11}$ は $3 p$ 行 $3 p$ 列の下三角行列を、 $R_{22}$ は $p$ 行 $p$ 列 の下三角行列を表す。

(3) 式 (12) の下三角行列 $R_{22}$ を特異值分解 211-する。

$$
R_{22}=\left[\begin{array}{ll}
S_{1} & S_{2}
\end{array}\right]\left[\begin{array}{cc}
\Sigma_{1} & 0 \\
0 & \Sigma_{2}
\end{array}\right]\left[\begin{array}{l}
V_{1}^{T} \\
V_{2}^{T}
\end{array}\right]
$$

ただし、 $\Sigma_{1}$ は $n$ 個の特異值が、 $\Sigma_{2}$ は $(p-n)$ 個の固有值がそ れぞれ值の大きなものから順に対角にならんだ行列であり、次 数 $n$ は特異值の大きさにより、各同定対象ごとに決定する。

(4) 行列 $S_{1}$ から、連続系システム行列 $A_{i}$ が離散化された行列 $A_{d i}$ を下式により求める。

$$
A_{d i}=S_{1}(1:(p-1), 1: n)^{+} S_{1}(2: p, 1: n)
$$

ただし、 $S_{1}(1:(p-1), 1: n)$ は $S_{1}$ の最初の $(p-1)$ 行より構成 される行列、 $S_{1}(2: p, 1: n)$ は $S_{1}$ の最後の $(p-1)$ 行から構成 される行列であり、+は擬似逆行列を表す。

(5) 離散系システム行列 $A_{d i}$ の固有值 $\hat{\lambda}$ を $j=\sqrt{-1}$ として、

$$
\hat{\lambda}=a+j b
$$

とおくと、次式のように固有振動数 $\omega_{i}$ が求まる ${ }^{20)}$

$$
\omega_{i}=\sqrt{\left\{\frac{1}{2 \Delta t} \ln \left(a^{2}+b^{2}\right)\right\}^{2}+\left\{\frac{1}{\Delta t} \tan ^{-1}\left(\frac{b}{a}\right)\right\}^{2}}
$$

\section{3. 数值解析による検討}

提案する手法の妥当性を検討するために、多層構造物モデルを対 象とした数值解析を行う。多層構造物モデルは、表 1 に示す 10 層 事務所ビルを想定した、10 自由度のせん断型構造物モデルとする。 構造物の総重量は約 $10,000 \mathrm{t}$ とし、1 次固有振動数を $0.83 \mathrm{~Hz} 、 2$ 次 固有振動数を $2.08 \mathrm{~Hz} 、 3$ 次固有振動数を $3.31 \mathrm{~Hz}$ とする。减衰は、 構造ヘルスモニタリングに用いる入出力データが加速度であること から、高次モードの影響も含むように、全てのモードについて、减 衰比が一律 0.02 となるように設定する。損傷した構造物モデルとし て、10 層と 1 層の岡性を 0.9 倍にしたモデル（以後、モデル D 1 と 表記）と 6 層、 4 層の剛性を 0.8 倍に、 5 層の剛性を 0.9 倍にしたモ デル（以後、モデル D2 と表記）の 2 種類を想定する。入力波はバ ンドリミテッドホワイトノイズとし、無損傷構造物モデル（以後、 モデルND と表記）と損傷構造物モデルで異なる波形を用いる。入 出力データは、常に構造物は振動していることから、サンプリング 時間間隔 $\Delta t=0.005$ 秒で、加振 5 秒後以降の 25 秒間の各層絶対加速 度応答および地表面加速度とする。またフィルタの状態量の初期值 はゼロに、係数 $\alpha$ は 0.1 に設定した。

本手法により同定した無損傷構造物モデル ND と損傷構造物モデ ルD1、D2 それぞれの式（10）で表される層剛性の評価值を表 2 に

表 1 対象構造物モデル

\begin{tabular}{ccc}
\hline 層 & 質量 [t] & 剛性 $[\mathrm{kN} / \mathrm{m}]$ \\
\hline 1 & 1000 & $1.60 \times 10^{6}$ \\
2 & 1000 & $1.51 \times 10^{6}$ \\
3 & 1000 & $1.42 \times 10^{6}$ \\
4 & 1000 & $1.30 \times 10^{6}$ \\
5 & 1000 & $1.18 \times 10^{6}$ \\
6 & 1000 & $1.04 \times 10^{6}$ \\
7 & 1000 & $8.90 \times 10^{5}$ \\
8 & 1000 & $7.20 \times 10^{5}$ \\
9 & 1000 & $5.40 \times 10^{5}$ \\
10 & 1000 & $3.20 \times 10^{5}$ \\
\hline
\end{tabular}

表 2 推定した層咸性の評価値 層剛性の評価値 $\left[1 / s^{2}\right]$

\begin{tabular}{cccc} 
層 & モデルND & モデル D1 & モデル D2 \\
\hline 1 & $1599\left(0.999^{*}\right)$ & $1439\left(0.999^{*}\right)$ & $1599\left(0.999^{*}\right)$ \\
2 & $1522\left(1.008^{*}\right)$ & $1526\left(1.011^{*}\right)$ & $1523\left(1.009^{*}\right)$ \\
3 & $1418\left(0.999^{*}\right)$ & $1419\left(0.999^{*}\right)$ & $1418\left(0.999^{*}\right)$ \\
4 & $1301\left(1.001^{*}\right)$ & $1303\left(1.003^{*}\right)$ & $1041\left(1.001^{*}\right)$ \\
5 & $1180\left(1.000^{*}\right)$ & $1181\left(1.001^{*}\right)$ & $1064\left(1.002^{*}\right)$ \\
6 & $1039\left(0.999^{*}\right)$ & $1040\left(1.000^{*}\right)$ & $832\left(1.000^{*}\right)$ \\
7 & $890\left(1.000^{*}\right)$ & $890\left(1.000^{*}\right)$ & $891\left(1.001^{*}\right)$ \\
8 & $720\left(1.000^{*}\right)$ & $720\left(1.000^{*}\right)$ & $720\left(1.000^{*}\right)$ \\
9 & $540\left(1.000^{*}\right)$ & $541\left(1.001^{*}\right)$ & $540\left(1.001^{*}\right)$ \\
10 & $320\left(1.001^{*}\right)$ & $288\left(1.002^{*}\right)$ & $321\left(1.002^{*}\right)$ \\
\hline \multicolumn{4}{c}{ * 推定值の真值1て対する比 }
\end{tabular}


示す。また表中の括弧の值は、推定值の真値に対する比を表す。表 2 より、ほぼ正確に層剛性を評価できることが確認できる。モデル D1、D2 それぞれの層剛性の評価值をモデル ND の層剛性の評価值 で割った層岡性の剛性低下率を表 3 に示す。表 3 より、損傷䈯所お よび層剛性の剛性低下率が本手法により正確に評価できることが確 認できる。

以上の数值解析より、本研究の手法により、加速度応答のみを用 いて層剛性の構造ヘルスモニタリングが可能となることを確認した。

\section{4. 実験による検訳}

提案する層剛性の構造ヘルスモニタリング手法の有効性を検証す る目的で、图 1 に示すような 8 層の小型構造物模型を用いた振動台 実験を行う。損傷後の剛性低下を表現するために、図 2 に示すよう な 2 層および 3 層の柱の総柱幅を 0.8 倍とする。そのため、理論的

\section{表 3 層岡性の剛性低下率}

\begin{tabular}{ccc}
\hline 層 & モデルD1 & モデル D2 \\
\hline 1 & 0.900 & 1.000 \\
2 & 1.003 & 1.001 \\
3 & 1.000 & 1.000 \\
4 & 1.002 & 0.801 \\
5 & 1.001 & 0.902 \\
6 & 1.000 & 0.800 \\
7 & 1.000 & 1.001 \\
8 & 1.000 & 1.001 \\
9 & 1.001 & 1.000 \\
10 & 0.900 & 1.001 \\
\hline
\end{tabular}

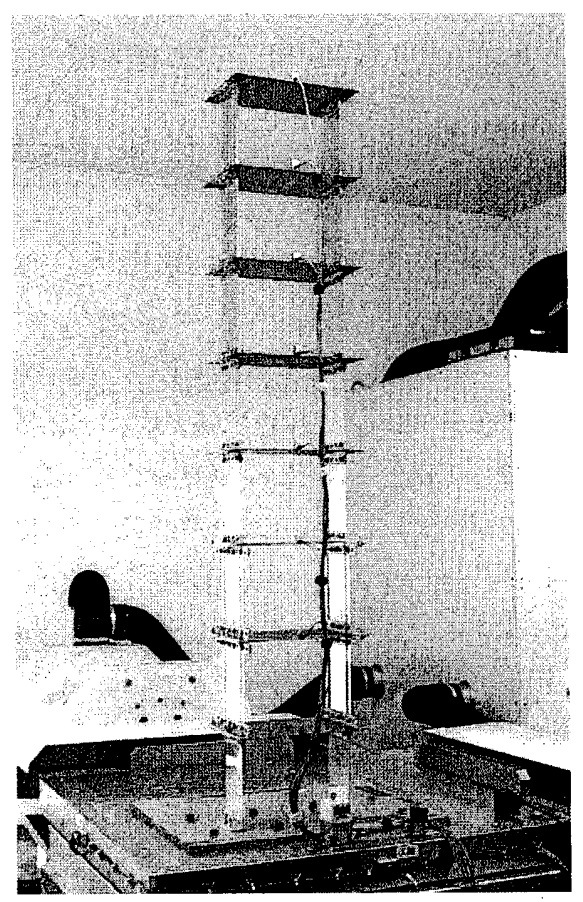

図 1 小型構造物模型
な剛性低下率は 0.8 となる。入力波として、無損傷時に対して 5 波、 損傷時に対して 5 波の合計 10 波の $60 \mathrm{~cm} / \mathrm{s}^{2}$ に基淮化したバンドリ ミテッドホワイトノイズを用いる。入出力データは、数值解析と同 様に、サンプリング時間間隔 $\Delta \mathfrak{t}=0.005$ 秒で加振 5 秒後から 25 秒間 計測した各層の絶対加速度応答と地表面加速度とし、フィルタの状 態量の初期值はゼロ、係数 $\alpha$ は 0.1 とする。また実験では、観測ノ イズの混入がさけられないことから、無損傷時、損傷時それぞれに 対し 5 回づつ層岡性の推定を行い、5 回の推定值の平均值を層岡性 の構造へルスモニタリングに用いることとした。

本手法により同定した無損傷時と損傷時それぞれについての式 （10）の層剛性の評価值を表 4、5 に示す。表 4、5より、入力によ らず、多少の相違はあるものの、層岡性をほぼ一定の值に評価でき ていることが確認できる。また無損傷時と損傷時の層剛性の評価值 の平均值より求めた各層の剛性低下率を、表 6 に示す。表 6 から、

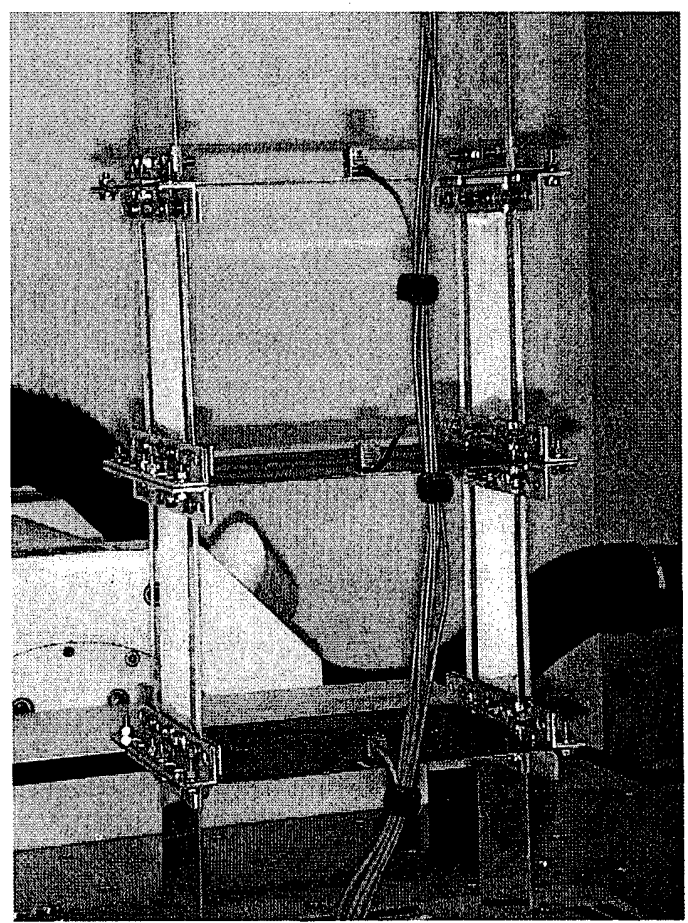

図 2 柱の㓮性低減部分

表 4 推定した層剛性の評価値（無損偒時）

層剛性の評価值 $\left[1 / \mathrm{s}^{2}\right]$

\begin{tabular}{ccccccc} 
層 & 1回目 & 2回目 & 3 回目 & 4回目 & 5 回目 & 平均値 \\
\hline 1 & 1933 & 1942 & 1944 & 1932 & 1954 & 1941 \\
2 & 1837 & 1773 & 1777 & 1758 & 1802 & 1789 \\
3 & 2123 & 2070 & 2091 & 2069 & 2051 & 2081 \\
4 & 2456 & 2476 & 2482 & 2472 & 2442 & 2466 \\
5 & 1303 & 1221 & 1217 & 1212 & 1257 & 1242 \\
6 & 1507 & 1560 & 1549 & 1758 & 1637 & 1602 \\
7 & 1565 & 1737 & 1713 & 1634 & 1826 & 1695 \\
8 & 1729 & 1729 & 1716 & 17331 & 1736 & 1728 \\
\hline
\end{tabular}


表 5 推定した層剛性の評価値（損㷅時）

層剛性の評価値 $\left[1 / s^{2}\right]$

\begin{tabular}{ccccccc} 
層 & 1 回目 & 2回目 & 3 回目 & 4回目 & 5 回目 & 平均値 \\
\hline 1 & 1986 & 2002 & 2023 & 2011 & 2007 & 2006 \\
2 & 1500 & 1504 & 1501 & 1496 & 1539 & 1508 \\
3 & 1755 & 1718 & 1694 & 1714 & 1697 & 1715 \\
4 & 2450 & 2465 & 2494 & 2492 & 2497 & 2480 \\
5 & 1198 & 1278 & 1204 & 1198 & 1260 & 1228 \\
6 & 1542 & 1526 & 1783 & 1495 & 1514 & 1572 \\
7 & 1634 & 1726 & 1816 & 1757 & 1540 & 1695 \\
8 & 1728 & 1707 & 1737 & 1747 & 1744 & 1733 \\
\hline
\end{tabular}

表 6 層剛性の㓮性低下事

\begin{tabular}{cc}
\hline 層 & 損傷時 \\
\hline 1 & 1.034 \\
2 & 0.843 \\
3 & 0.824 \\
4 & 1.006 \\
5 & 0.988 \\
6 & 0.981 \\
7 & 0.999 \\
8 & 1.003 \\
\hline
\end{tabular}

2 層および 3 層が損傷層となり、本手法により正確な損傷層の特定 が可能となることが確認できる。また、2 層の層岡性の低下率が 0.843 、 3 層の層剛性の低下率が 0.824 となっており、2 層および 3 層の層剛 性がほぼ想定した剛性低下率と等しくなっており、本手法により層 剛性の損傷度が把握できることが確認できる。

以上、観測ノイズの混入をさけられない実験においても、提案手 法により、加速度応答のみを用いて層岡性の構造へルスモニタリン グが可能となることを確認し、本手法の有効性を検証した。

\section{5. まとめ}

本研究では、簡便で精度の高い、加速度計測による層岡性の構造 ヘルスモニタリング手法を提案し、その有効性を数值解析および小 型構造物模型による振動台実験により示した。

提案手法は、対象層とその上下層の絶対加速度計測のみで、層剛 性の剛性低下率を把握できるため、全層もしくは対象層より上部の 全層の同期した応答計測を必要としない。また、各層独立に構造へ ルスモニタリングを行うため、対象層のみの構造へルスモニタリン グが可能となる。そのため提案手法は、構造物全体を一括して構造 ヘルスモニタリングする必要性も、上層から順に構造ヘルスモニタ リングする必要性もなく、実用的な手法になりえる。

\section{参考文献}

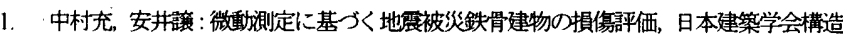
釆論文集，No.517，pp.61-68，1999.3

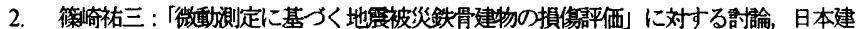
築学会構造系論文集，No.535，pp.179-180，2000.9

3. 中村充, 安井培: 篠㥓祐三氏の討論に対する回答, 日本建筑学会構造系論文集, №.535, pp.180-181, 2000.9

4. S.W.Doebling, C.R.Farar, M.B.Prime, D.W.Shevitz : Damage identification and health monitoring of structural and mechanical system from changes in their vibration characteristics : A literature review, Las Alamos Report, LA-13070-MS, 1996.5

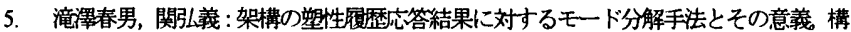
造工学論文集，日本建築学会，V6l.32B，pp.89-100，1986.3

6. 滝澤春男 : 梁崩壊型勒性架構の動的機構形成における定モード成分の抽出, 構造工学 論文集，日本建筑学会，Vol.36B，pp.245-258，1990.3

7. 濱本卓司，近藤一平：鉛直・办平方向探卖を用いた偏心を有する多層建勧物の一段皆 損賃検出，日本建築学会構造系論文集，No.519，pp.21-28，1999.5

8. 演本卓司, 森田高市，勅使川原正臣 : 複数モ一ドの固有振動数变化を用いた多層建築 物の損稘険出，日本建案学会構造系論文集，No.560，pp.93-100，2002.10

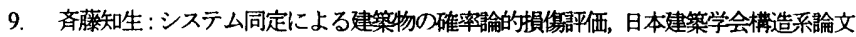
集, No.557, pp.93-100, 2002.7

10. 吉本怜毅，三田彰，森田高市: 振動モードとセンサ一特性を考庶した構造物の並列処 理型損傷同定，構造工学論文集，日本建築学会，Vol.48B，pp.487-492，2002.3

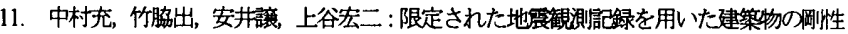
と減衰の同時同定，日本建築学会構造系論文集，No.528，pp.75-82，2000.2

12. I.Takewaki, M.Nakamura : Stiffness-damping simultaneous identification using limited earthquake records, Earthquake Engmeering and Sinctural Dymamics, Vol.29, No.8, pp.1219$1238,2000.8$

13. 池田芳榯, 仁田佳宏：一般化 Maxwell モデルの時間領域におけるシステム同定，構 造工学論文集，日本建筑学会，V6l.47B，pp.97-103，2001.3

14. 仁田佳宏，池田芳樹，西谷章 : Maxwell 要素が組み込まれた質点系モデルのオンラ イン同定，日本建築学会大会学術鞾演㤦概集（東京)，構造I，pp.293-294，2001.9

15. 仁田佳厷，西谷章: Maxwell ダンパガ組み込まれた質点系モデルのオンライン同定， 第2 回ダンピングシンポジウム「ダンピンク技術の新しい展開」講演論文集，日本機 械学会, pp.350-353, 2002.1

16. M.Verhaegen P.Dewilde : Subspace model identification Part 1. The output-enror state-space model identification algorithm, Intermational Joumal of Control, Vbl.56, №.5, pp.1187-1210, 1992.5

17. 片山徹: 部分空間法によるシステム同定一実現理論からの接近, システム制御情報, Vol.41, No.9, pp.380-387, 1997.9

18. 足立修，永田寛，山口功，木田隆，関口毅 : ETS-VI 軌道上同定夷倹デー夕による 予測誤差法と部分空間法の比較，計測自動制御制御学会論文集，Vl.33，No.8， pp.805-811, 1997.8

19. 上林雅子, 三田彰: 部分空間法による制振構造物のシステム同定, 日本建築学会大会 学術撞演梗概集（北陸），B-2，pp.983-984，2002.8

20. C.S.Huang, H.L.Lin : Modal identification of structures from ambient vbration, free vibration, and seismic response data via a subspace approach, Earhhuake Engineering and Sirnuctural Dynamics, Vol.30, No. 12, pp.1857-1878, 2001.12

21. 片山徹 : システム同定入阴，朝倉書店，1994

22. L.Ljung : System Identification: Theoryfor User, Second Edition, Prentice Hall, 1999

23. 伊理正夫: 岩波講座 応用数学 線形代数 I, 岩波書店, 1993

(2003年 4 月 9 日原稿受理，2003年 8 月 20 日採用決定) 